\title{
The reality of dreams
}

\author{
Niranjan Babu A, Lakshmi Ranganathan, Nagarajan \\ Ramakrishnan \\ Nithra Institute of Sleep Sciences, Chennai, Tamil Nadu, India.
}

DOI No: 10.5958/0974-0155.2015.00003.0

Indian J Sleep Med 2015; 10.1, 22-28

\begin{abstract}
A series of images, ideas, emotions, and sensations that happen involuntarily in the mind at the time of sleep are known as dreams. A definite understanding of the content and purpose of dreams is not yet established. They have frequently been a subject of scientific assumption and a focus of philosophical and religious interest.

Although there are several studies on dreams, there is no concrete evidence or explanation on purpose, occurrence, or consistency. The objective of this article is to review available literature on dreams with a specific focus on the character, content, and types of dreams.

Keywords: dreams, sleep, dream recall, memory, lucid dreams, REM and NREM.
\end{abstract}

\section{Introduction}

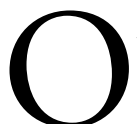

neirology refers to the scientific study of dreams. Dreaming is a state featured by sensory, cognitive, and emotional incidences during sleep. Dreams usually occur 3-6 times per night and lasts for 5-20 $\mathrm{min}$. It has been shown that nearly $95 \%$ of dreams are forgotten and only $48 \%$ of people who appear in a dream are identified by the person dreaming ${ }^{1-2}$.

It was earlier believed that dreams occur only during rapid eye movement (REM) stage of sleep. However, it is now understood that dreams may occur at other stages as well but are more likely to be recalled when they occur during REM sleep ${ }^{3}$.

\section{Address for correspondence}

\section{Dr. Nagarajan Ramakrishnan}

Director

Nithra Institute of Sleep Sciences,

Door \# 29, Plot \# 1997, J Block, $13^{\text {th }}$ Main Road, Anna Nagar, Chennai 600 040,

Tamil Nadu, India

Email: ram@nithra.com

Indian Journal of Sleep Medicine (IJSM), Vol. 10, No. 1, 2015
Ancient Indian Upanishads consider dreams as a third state, the other two being wakefulness and sleep. Greek and Mesopotamians considered dreams to be messages from God or from the dead. Sigmund Freud, father of psychoanalysis, regards dreams as manifestations of deepest desires and anxieties, often relating to repressed childhood memories or obsessions $s^{4}$. Carl Jung, the founder of analytical psychology, expanded on Freud's idea that dream content relates to the dreamer's unconscious desires ${ }^{5}$. Neurologists and neuroscientists explain dreams through different theories such as excitation of long-term memoriesor strengthening of semantic memories ${ }^{6-17}$.

Although there are many beliefs, theories and studies, there is no concrete evidence or explanation on purpose, occurrence, or consistency of dreams. We aim to explore the literature to summarize the current concepts on dream with a specific focus on character, content, and types. 


\section{Materials andMethods}

Literature search was performed in PUBMED using the keyword "dreams" through August 2015. The search revealed around 8,046 articles. The search was narrowed by selecting only those that focus on character, content, and types of dreams in keeping with the objectives of this article, and 51 articles were selected for further detailed review.Abstracts were also included for review. However, studies on neuroanalysis, psychoanalysis, and autobiographical memory concepts of dream were not included.

\section{Themes in Dreams}

Dreams with same content reported bymostof the dreamers refer to typical dreams. The frequencies of typical dream themes have been studied by Ciric P et al., and the study indicated thatthere were 55 typical dream themes, which were same over different sample populations ${ }^{18}$. There are 12 themes that have been identified as most common in dreams (Table 1$)^{19}$.

Table 1: Common themes in dreaming

\begin{tabular}{|l|l|}
\hline- & Falling \\
\hline - & Teeth falling out \\
\hline - & Showing to work or school naked \\
\hline- & Taking a test \\
\hline - & Dying \\
\hline - & Meeting a celebrity \\
\hline- & Being chased \\
\hline - & Partner cheating \\
\hline- & Showing up late to a meeting \\
\hline- & Flying \\
\hline$\bullet$ & Being pregnant \\
\hline$\bullet$ & Driving in an out of control vehicle \\
\hline
\end{tabular}

\section{Types of Dreams}

\section{Nightmares}

The contents of 9,796 dream reports were collected and studied by Pilon $\mathrm{M}$ et al., ${ }^{20}$ which revealed 253 nightmares and 431 bad dreams. Nightmares often contained physical violence, circumstances that were stranger, emotionally strong, more failures, and unfortunate conclusions; $35 \%$ of these nightmares featured chief emotions other than fear. Bad dreams often contained interpersonal fights and $55 \%$ of these dreams featured major emotions other than fear.

Erlacher et al. studied the dreams of 840 German athletes from various sports ${ }^{21}$. It was found in this study that about $15 \%$ of the athletes experienced at least one upsetting dream previous toa significant competition or game. A nearly equal number of athletes revealed at least one upsetting dream in their sports profession. Athletic failures were often related to reported dream content.

\section{Recurrent dreams}

A recurrent dream is one that repeats and occurs on a regular basis during sleep.A studyof 212 recurrent dreams by Zadra et $\mathrm{a}^{22}$. showed that one or more threats were observed in $66 \%$ of these dreams. The threats seemed to be hazardous and targeted at the dreamer, and the dreamer took the more usual and reasonable defensive action to face the threat. Less than $15 \%$ of the repeated dreams showed realistic and or likely circumstances that were dangerous for survival or reproductive success, but when dreaming, these dreamers were rarely successful to evade the situation. The study also showed that repeated dreams in adults were related to poor psychological well-being and proposed that children recording repeated dreams are also probable to revealworse psychosocial adjustment than children without repeateddreams.

\section{Lucid dreams}

A dream in which the dreamer is aware of the dreaming state is deemed to be a lucid dream. Research has revealed that lucid dreaming is associated with an enhanced activation of parts of the brain that are typically repressed during sleep.

A German study has shown that there is a significant increase in the brain activity during the lucid dreaming state. The authors found that there was an intensified activity in the frontal and fronto lateral parts of the brain, which are the places of language thought and higher mental functions related to self-awareness. This supports the concept that lucid dreaming is an exclusive state of consciousness distinct from any other mental states.

Indian Journal of Sleep Medicine (IJSM), Vol. 10, No. 1, 2015 
Patients with narcolepsy have been shown to have higher rates of lucid dreaming than general population and they also have high rate of dream recall ${ }^{23}$.

\section{Day dreams and nap dreams}

Carrand Nielson ${ }^{24}$ studied daytime nap dreams (REM and non-REM [NREM]) and compared these with each other and with day dreams. Fifty-one subjects underwent daytime naps (with REM or NREM awakenings) and furnished both waking day dream and nap dream records. Increased recall rates for REM (96\%) and NREM (89\%) naps were shown when compared with representative recall rates for night time dreams $(80 \%$ and $43 \%$, respectively), suggestive of an increased circadian effect. REM dreams showed higher rate of emotional intensity and sensory experience compared with NREM dreams.

\section{Characters in Dreams}

A study by Kahn et al. on 320 adults showed that $48 \%$ of characters seen in dreams signified a named person who the dreamer aware of, $35 \%$ of characters were recognized by their social role, and $16 \%$ were unidentified $^{25}$. Among named characters, characters were identified by appearance (32\%), behavior (21\%), face $(45 \%)$, and just knowing (44\%). Features of bizarreness were observed in $14 \%$ of named and generic characters. The study also examined the connection between dream emotion and dream character identification. Affection and happiness were generally linked with known characters and aided in recognizing them even when these emotional characteristics were varying with those of the waking state.

\section{Memory of Dreams}

Memories of day today activities sometimes incorporate into dreams. A study by Fischer et al. has shown that REM sleep might counteract the intentional suppression of memories, which makes them more accessible for recovery ${ }^{26}$. Two types of temporal effects have been shown to characterize the incorporation of memories into dreams. These include the day-residue effect, involving incorporations of events from the preceding day, and the dream-lag effect, involving incorporations delayed by about a week.
The findings of Nielsen et al. are constant with the probability that processing memories into dream integration takes around 7 days and this in turn helps memory consolidation ${ }^{27}$.

\section{Colors in Dreams}

A study by Okada $\mathrm{H}$ et $\mathrm{al}^{28}$ showed that about $80 \%$ of subjects younger than 30 years dreamt in color whereas only $20 \%$ subjects elder than 60 years said they dreamt in color. The number of people in their 20s, 30s, and 40s dreaming in color increased from 1993 to 2009. Investigators speculate that there might be a role of color television in this difference.

Another research by Murzyn $\mathrm{E}^{29}$ involving both questionnaires and dream diaries showed that older adults experienced more black and white dreams than the younger subjects. Older people stated that they experienced brightness in both their color and black and white dreams equally. However, younger subjects reported that their black and white dreams were of worse quality.

\section{Characteristics of Dreams in General Population}

\section{Age}

Aging is often associated with changes in sleep timing, structure, and electroencephalographic activity. Scientific work approves that dream memory gradually decreases from the commencement of adulthood and that dream reports become less powerful with age. This development happens quicker in men than women, and gender variations in the content of dreams have also been recorded $^{30}$.

\section{Gender}

A study by Rubinstein and Krippner, with 108 male and 110 female participants, found no differences between the content of dreams between the two groups-specifically in terms of aggression, friendliness, sexuality, characters, weapons, or clothes that featured in their dreams. However, women's dreams were characterized by increased number of family members, babies, children, and indoor surroundings than men. ${ }^{31}$ 


\section{Dreams in children}

Kessel $\mathrm{s}^{32}$ in his study investigated anxiety dreams in 103 children aged 9-11 years and recorded that girls revealed an increased incidence of anxiety dreams than boys, although they could not recollect their dreams more often. The frequency of dreams was more in girls than boys and featured about the loss of another person, falling, of socially worrying conditions and small animals, animals as attackers, family members (mainly siblings), and other female subjects of known identity.

Muris $\mathrm{P}$ et $\mathrm{a}^{33}$ showed that Fear $(75.8 \%)$, worries $(67.4 \%)$, and scary dreams $(80.5 \%)$ were the anxiety symptoms note in a study comprising 190 normal school children aged 4-12 years. Anxiety of scary dreams was generally observed in children aged 4-6 years, which dominated even more higher in children aged 7-9 years, but their incidence reduced in children aged 10-12 years.Variations in categories of fears, worries, and dreams were observed across age groups, with fears and scary dreams relating to imaginary creatures reducing with age and worries about test performance increasing with age.

\section{Dreams in pregnancy}

Studies done by Lara-Carrasco et al., comparing the dreams of pregnant and nonpregnant women, ${ }^{34,35}$ have shown that pregnant group experienced more dreams with the theme relating to pregnancy, childbirth, and fetus. Childbirth theme was more observed in late than in early third trimester. Pregnant women experienced more morbid elements in their dreams than the non pregnant group.

\section{Dreams in Specific Patient Groups}

\section{Dreams in migraine}

In a study that evaluated dreams in people experiencing various types of headaches, it was found that people with migraine revealed higher incidences of taste- and smellrelated dreams, suggesting there could be involvement of cerebral structures, such as amygdala and hypothalamus, in migraine mechanisms and in the biology of sleep and dreaming ${ }^{36}$.

\section{Dreams in pain}

In a study by Raymond et al., 28 non ventilated burn victims were questioned about their dreams for five consecutive mornings during their first week of hospitalization. The results found were $39 \%$ of patients reported pain dreams, of which $30 \%$ was only totally pain related. These patients revealed evidences of poor sleep, increased nightmares, intense pain during therapeutic procedures, and higher consumption of anxiolytic medication. More than half of the patients did not record pain dreams; however, these results were suggestive that pain dreams happen at a higher incidence in suffering populations than in normal participants ${ }^{37}$.

\section{Dreams in depression}

In a study by Firth et al, The dream content of psychiatric in-patients who were admitted because of suicidal attempts were compared with three inpatient control groups who were admitted for (i) depression and suicidal ideation without attempt, (ii) depression with no suicidal ideation, and (iii) commission of a violent act without suicide.

Results of the study showed that both suicidal and violent patients revealed higher death content and damaging violence in their dreams. This was a function of the severity of depression and few character personalities, such as impulsivity, and not particular to the patient's behavior itself ${ }^{8}$.

A study by Marinova et al. on 52 inpatients experiencing depression revealed that depressed patients with nightmares showed considerably increased risk of suicide. Depression seemed to be a risk factor for suicidal behavior when associated with nightmares ${ }^{39}$.

\section{Dreams in bereavement}

In the study by Wright et al. on 278 bereaved individuals,${ }^{40}$ it was noted that $58 \%$ of participants revealed dreams of their dead loved ones, with variable levels of incidences. Majority of the revealed that their dreams were either enjoyable or both enjoyable and worrying, and few recorded entirely disturbing dreams. Predominant dream contents comprised enjoyable memories or experiences, the deceased free of illness, remembrances of the deceased's illness or death time, the deceased in the life after death appearing relaxed and at peace, and the deceased communicating a message. Sixty percentage of subjects felt that their dreams impacted their grief process.

Indian Journal of Sleep Medicine (IJSM), Vol. 10, No. 1, 2015 


\section{Factors That Influence Dreams}

\section{Sleep disorders}

According to the review article by Schredl, dream recall is more in patients with insomnia, and their dreams reflected the stress pertaining to their condition, but, in sleep apnea patients, this is rare. Patients with narcolepsy were shown to have more bizarre and negatively toned dreams ${ }^{41}$.

In another study, researchers showed that, in a test group of 393 subjects, $71.4 \%$ patients without sleep apnea were able to recollect their dreams, but those with severe obstructive sleep apnea revealed a significantly reduced incidence of dream recall. The study results also showed that patients with sleep apnea could not recall their nightmares ${ }^{42}$.

\section{Medications}

Clinical knowledge and a few published studies have reported that selective serotonin reuptake inhibitors (SSRIs) strengthen dreaming. Tribl et al. reviewed 21 clinical studies and 25 case reports on the effect of antidepressants on dreaming ${ }^{43}$. The review showed that tricyclic antidepressants induced more positive dream emotions. In both depressed patients and healthy volunteers, there was a decrease of dream recall frequency with antidepressant use. Nightmares were caused by withdrawal from tricyclic antidepressants and monoamine oxidase inhibitors, phenelzine and tranylcypromine, while intensified dreams were reported after withdrawal of SSRIs/serotonin-norepinephrine reuptake inhibitors.

\section{Alcohol}

A study by Steinig et al., which examined the sleep quality and the subjective dream experience in alcohol-dependent patients during withdrawal and self-denial compared with healthy control subjects, found that patients with alcohol dependency during withdrawal and self-denial dreamt considerably more frequently about alcohol. Subjective sleep and dream quality is highly impaired in patients with alcohol dependency ${ }^{44}$.

\section{Dreams and Stages of Sleep}

One study by Takeuchi et $\mathrm{al}^{45}$. hypothesized that various physiological processes trigger dreaming during REM and NREM sleeps. They concluded that although both
REM and NREM sleeps experience dreaming, dreams recorded from these periods vary considerably in both quality and quantity and are likely to be formed by various processes.

In another study, visual imagery was recorded more frequently, after arousals from REM compared with stage 2 sleep; $83 \%$ of REM arousals compared with only $34 \%$ stage 2 arousals occasioned in imagery reports ${ }^{46}$.

Cortisol is also proposed to play a vital role in governing the memory systems' states during sleep. High levels of cortisol, observed during REM sleep, disrupt normal hippocampal to neocortical communication, which interferes with the form of memory consolidation, and, hence, the content of dreams is also affected ${ }^{47}$.

\section{Recalling Dreams}

Dream investigators determine that about $95 \%$ of all dreams are disremembered completely upon awakening. Occasionally, a dream is unexpectedly recalled later in the day or on another day, suggestive that the memory is not completely lost but, for some cause, it may have been problematic to remember ${ }^{48}$.

In a French study, ${ }^{49}$ researchers performed brain scans on 41 people both when awake and during sleep. Of the subjects, 21 recollected dreams about five mornings per week and were categorized as "high dream recallers," while the remaining 20 recalled dreams only two mornings per month and were categorized as "low dream recallers." During both asleep and awake, the high dream recallers revealed enhanced levels of activity in the brain's medial prefrontal cortex and temporoparietal junction. Brain lesion and neuroimaging findings unite in demonstrating that the temporo-parieto-occipital junction and ventromesial prefrontal cortex play vitalroles in dream remembrance.

\section{Conclusion}

Dream research remains a challenge, and current evidence is limited. Dreams occur in all stages of sleep; but, those that occur during REM sleep are more likely to be recalled. Age, gender, and sleep disorders are common factors that affect dreams. Sleep-related disorders such as narcolepsy lead to negatively toned dreams and lucid dreams. Available literature shows that there is a connecting link between real-life events and dreams. 


\section{References}

1. The American Heritage Dictionary of the English Language, 4th ed. Boston, MA: Houghton Mifflin Hartcourt; 2000. RetrievedMay 7,2009.

2. Kavanau JL. Sleep, memory maintenance, and mental disorders.J Neuropsychiatry ClinNeurosci2000;12: 199-208.

3. Hobson JA. REM sleep and dreaming: towards a theory of protoconsciousness. Nat Rev Neurosci2009;10:803-13.

4. Freud S The Interpretation of Dreams (1900)

5. Jung:London: Hogarth Press; 1964, p. 21.

6. Tsoukalas I. The origin of REM sleep: A hypothesis. Dreaming 2012;22:253-83.

7. Vitelli R. Exploring the mystery of REM sleep. Psychology Today, Online blog, March 25, 2013.

8. Solms M. Dreaming and REM sleep are controlled by different brain mechanisms. Behav Brain Sci. 2000;23: 843-50.

9. Zhang J. Memory process and the function of sleep. J Theoret2004;6:1-7.

10. Zhang J. Continual-activation theory of dreaming. Dynam Psychol2005. Retrieved March 13, 2006.

11. Tarnow E. How dreams and memory may be related. Neuro-Psychoanalysis 2003;5:1-12.

12. The Health Benefits of Dreams. Available at: Webmd.com. February 25, 2009. RetrievedAugust1 1,2012.

13. Stickgold R, Hobson JA, Fosse R, Fosse M. Sleep, learning, and dreams: off-line memory reprocessing. Science2001; 294 (5544):1052-7.

14. Payne JD, Nadel L. Sleep, dreams, and memory consolidation: the role of the stress hormone cortisol.Learn Mem2004;11:671-8.

15. Robert W. Der Traumals Naturnothwendigkeiterklärt. Zweite Auflage, Hamburg: Seippel; 1886.

16. Evans C, Newman E. Dreaming: an analogy from computers. New Scientist1964;419:577-9.

17. Crick F,Mitchison G. The function of dream sleep.Nature 1983;304:111-4.

18. Ciric P, Schredl M, Götz S, Wittmann L. Typical dreams: stability and gender differences.JPsychol $2004 ; 138$ : 485-94.

19. Wallace I. The Dr. Oz Showand Anderson Cooper 360. Grant R.The Complete A to Z Dictionary of Dreams. Lawrence L. The Illustrated Dream Dictionary.New York Daily. Newscolumn on dream analysis.

20. Pilon $\mathbf{M}$, Zadra, Donderi DC. Variety and intensity of emotions in nightmares and bad dreams.JNervMentDis $2006 ; 194: 249-54$

21. Erlacher D, Ehrlenspiel F, Schredl M. Frequency of nightmares and gender significantly predict distressing dreams of German athletes before competitions or games.JPsychol 2011;145:331-42.
22. Zadra A, Desjardin S, Marcotte E. Evolutionary function of dreams: a test of the threat simulation theory in recurrent dreams.Conscious Cogn 2006;15:420-63.

23. Dodet P, Chavez M, Leu-Semenescu S, Golmard JL, Arnulfl.Lucid dreaming in narcolepsy.Sleep 2015;38: 487-97.

24. Carr $\mathbf{M}$, Nielsen T. Day dreams and nap dreams: content comparisons. ConsciousCogn. 2015;6:196-205.

25. Kahn D, Stickgold R, Pace-Schott EF, Hobson JA. Dreaming and waking consciousness: a character recognition study. JSleep Res 2009;9:317-25.

26. Fischer S, Diekelmann S, Born J. Sleep's role in the processing of unwanted memories. J Sleep Res $2011 ; 20: 267-74$.

27. Nielsen TA, Kuiken D, Alain G, Stenstrom P, Powell RA. Immediate and delayed incorporations of events into dreams: further replication and implications for dream function. JSleep Res 2004;13:327-36.

28. Okada $\mathbf{H}$, Matsuoka K, Takao H. Life span differences in color dreaming. Dreaming 2011;21:213-20.

29. Murzyn E. Do we only dream in colour? A comparison of reported dream colour in younger and older adults with different experiences of black and white media. Conscious Cogn 2008;17:1228-37.

30. Guénolé F, MarcaggiG, Baleyte JM, Garma L. [Dreams in normal and pathological aging]. PsycholNeuropsychiatr Vieil 2010;8:87-96.

31. Rubinstein K, Krippner S.Gender differences and geographical differences in content from dreams elicited by a television announcement.Int JPsychosom 1991;38:40-4.

32. Kessels T. Fear in dreams of 9- to 11-year-old children. Prax Kinderpsychol Kinderpsychiatr 2004;53:19-38.

33. Muris P, Merckelbach H, Gadet B, Moulaert V.Fears, worries, and scary dreams in 4- to 12-year-old children: their content, developmental pattern, and origins.J ClinChild Psychol 2000;29:43-52.

34. Lara-Carrasco J, Simard V, Saint-Onge K, LamoureuxTremblay V, Nielsen T.Maternal representations in the dreams of pregnant women: a prospective comparative study.Front Psychol 2013;4:551.

35. Dagan $Y$, Lapidot A, Einsentein M.Women's dreams reported during first pregnancy.Psychiatry ClinNeurosci 2001;55:13-20.

36. Lovati C, DeAngeli F, D'Amico F, et al.Isthe brain of migraineurs"different" even in dreams? NeurolSci 2014;35Suppl 1: 167-9.

37. Raymond I, Nielsen TA, Lavigne G, Choinèire $M$. Incorporation of pain in dreams of hospitalized burn victims.Sleep 2002;25:765-70.

38. Firth ST, Blouin J, Natarajan C, Blouin A. In comparison of the manifest content in dreams of suicidal, depressed and violent patients.Can JPsychiatry 1986;31:48-53.

39. Marinova P, Koychev I, Laleva L, et al. Nightmares and suicide: predicting risk in depression.PsychiatrDanub 2014;26:159-64.

Indian Journal of Sleep Medicine (IJSM), Vol. 10, No. 1, 2015 
40. Wright ST, Kerr CW, Doroszczuk NM, Kuszczak SM, Hang PC, Luczkiewicz DL. The impact of dreams of the deceased on bereavement: a survey of hospice caregivers. Am JHosp Palliat Care 2014;31:132-8.

41. SchredI M. Dreams in patients with sleep disorders. Sleep Med Rev 2009;13:215-21.

42. Pagel JF, Kwiatkowski C. The nightmares of sleep apnea: nightmare frequency declines with increasing apnea hypopnea index. J Clin Sleep Med 2010;6:69-73.

43. Tribl GG, Wetter TC, Schredl M. Dreaming under antidepressants: a systematic review on evidence in depressive patients and healthy volunteers. Sleep Med Rev2013;17:133-42.

44. Steinig J, Foraita R, Happe S, Heinze M. Perception of sleep and dreams in alcohol-dependent patients during detoxication and abstinence.Alcohol Alcohol $2011 ; 46: 143-7$.
45. Takeuchi T, Miyasita A, Inugami M, Yamamoto Y. Intrinsic dreams are not produced without REM sleep mechanisms: evidence through elicitation of sleep onset REM periods. JSleep Res $2001 ; 10: 43-52$.

46. Conduit R, Crewther SG, Coleman G. Spontaneous eyelid movements (ELMS) during sleep are related to dream recall on awakening. JSleep Res 2004;13:137-44.

47. Payne JD, Nadel L.Sleep, dreams, and memory consolidation: the role of the stress hormone cortisol. Learn Mem 2004;11:671-8.

48. International Association for the Study of Dreams, RetrievedOctober 21, 2014.

49. French National Institute of Health and Medical Research (INSERM), News release, February 12, 2014. 